\title{
Improvement of atmospheric pollution in the capital cities of US during COVID-19
}

\author{
Ritvik Mishra ${ }^{1} \cdot$ Akshansha Chauhan $^{2} \cdot$ Ramesh P. Singh $^{3}$ (D) N. C. Mishra ${ }^{4} \cdot$ Rozalin Mishra $^{5}$
}

Received: 17 June 2021 / Accepted: 27 August 2021 / Published online: 7 September 2021

(c) The Author(s), under exclusive licence to Springer Nature Switzerland AG 2021

\begin{abstract}
The spread of COVID-19 during 2020 impacted the whole world and still affecting the lives of people living in some parts of the world. The spread of this epidemic started in the US in late March 2020 and became a major issue in April due to an outburst of COVID-19 cases. Most of the countries in the world imposed complete to partial lockdown, but in the US, few states imposed lockdowns. Even after the advisory of the various Government department, the mobility data suggest that there was an enhancement (10-15\%) in mobility during March 2020. Later sudden drop in mobility was observed during April 2020. The fall in aerosols optical depth (AOD), particulate matter concentration, $\mathrm{NO}_{2}$, and Ozone are observed along with the positive shifts in the $\mathrm{SO}_{2}$. In some of the states, AOD shows pronounced decline during May and June (5-40.90\%), in the month of May more than $80 \%$ decline was observed compared to the month of June 2020. In the month of April 2020, up to $73.64 \%$ decline was observed in $\mathrm{NO}_{2}$, and $70-99 \%$ in the months of May and June 2020. We found a good relationship between the mobility data and improvement in the air quality of the US. The changes were not significant compared to other countries in the world due to scattered lockdown policy, but in the US a pronounced change is observed during April month compared to March and May.
\end{abstract}

Keywords COVID-19 $\cdot$ PM2.5 $\cdot$ Air Quality $\cdot$ AOD $\cdot$ EPA $\cdot$ Ozone $\cdot$ MODIS $\cdot \mathrm{NO}_{2} \cdot$ Aerosol

\section{Introduction}

The spread of COVID-19 affected a large population of the world and caused huge deaths across the globe (https:// ourworldindata.org/, WHO 2021a). Wuhan city, China was the epicenter of this deadly virus and it spread due to the movement of people at the beginning from this city to other countries for business and tourism (Chauhan and

Ramesh P. Singh

rsingh@chapman.edu

1 Cosumnes Oak High School, 8350 Lotz Parkway, Elk Grove, CA 95757, USA

2 Center for Space and Remote Sensing Research, National Central University, Taoyuan 32001, Taiwan

3 School of Life and Environmental Sciences, Schmid College of Science and Technology, Chapman University, Orange CA-92866, USA

4 Trinity Technology Group, Suite 105, 2015 J Street, Sacramento, CA 95757, USA

5 Pacific Gas \& Electric, 3136 Boeing Way, Stockton, CA 95204, USA
Singh 2020, 2021; Gharehgozli et al. 2020; Rajbhandari et al. 2020; Singh and Chauhan 2020; Wang et al. 2020; Chinazzi et al. 2020; Gilbert et al. 2020; Liu et al. 2020; WHO 2021b). COVID-19 spreads in the US, Europe, and other countries slowly, no country remained safe with this virus (Fig. 1a). Some of the countries immediately took steps to mitigate the spread of COVID-19 and in this connection, India and some of the European countries took lead to imposed lockdown. In US Universities, schools, private companies, and industries asked their employees to work remotely. The teaching started remotely, and US Governors advised people living in their states to maintain social distancing, use of sanitizer, and frequent washing of hands, despite efforts, people were spending time at the beaches and moving from one place to other places, even flights were operational although the frequency of these flights was significantly cut down. In the beginning, scientists were unaware of the virus and nature of the virus, social distancing, use of sanitizer, and washing of hands were common practices to mitigate the impacts of COVID-19. Most of the countries, China, India, the UK, Italy, Spain, the USA, and many others have imposed 
(a)

Cumulative confirmed COVID-19 deaths per million people, Mar 19, 2021

Limited testing and challenges in the attribution of the cause of death means that the number of confirmed deaths may not be an accurate count of the true number of deaths from COVID-19.
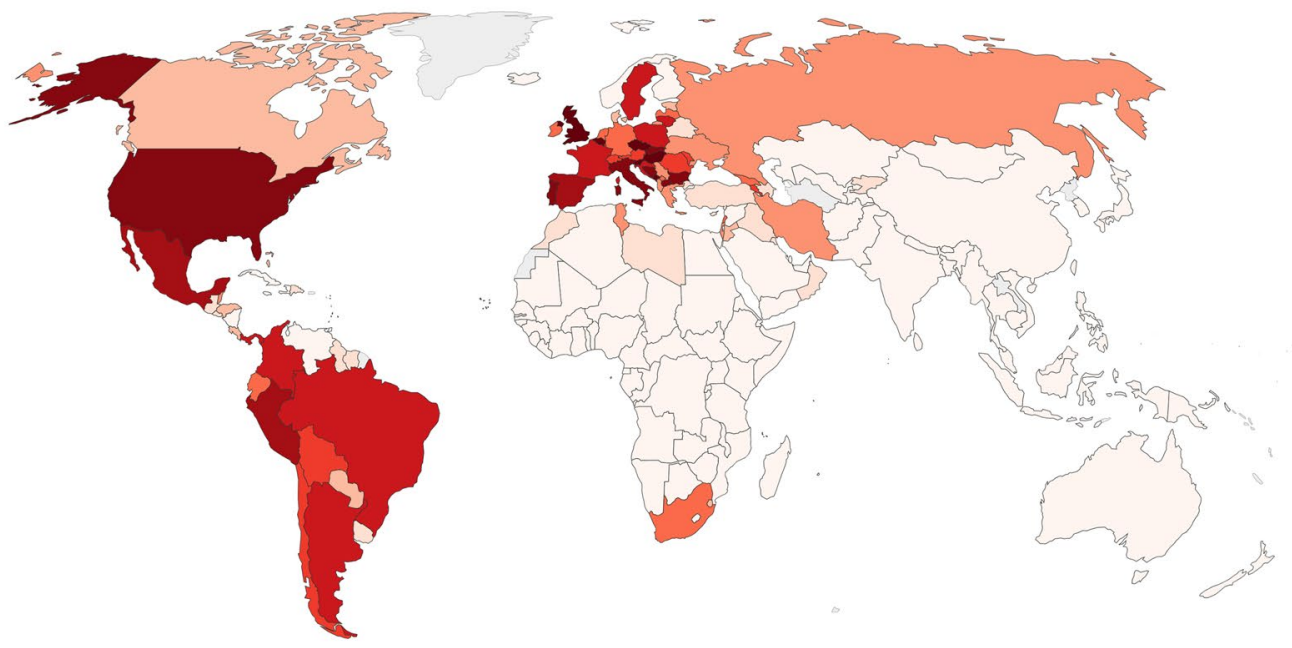

No data 0

$600 \quad 800$

1,000

(b)

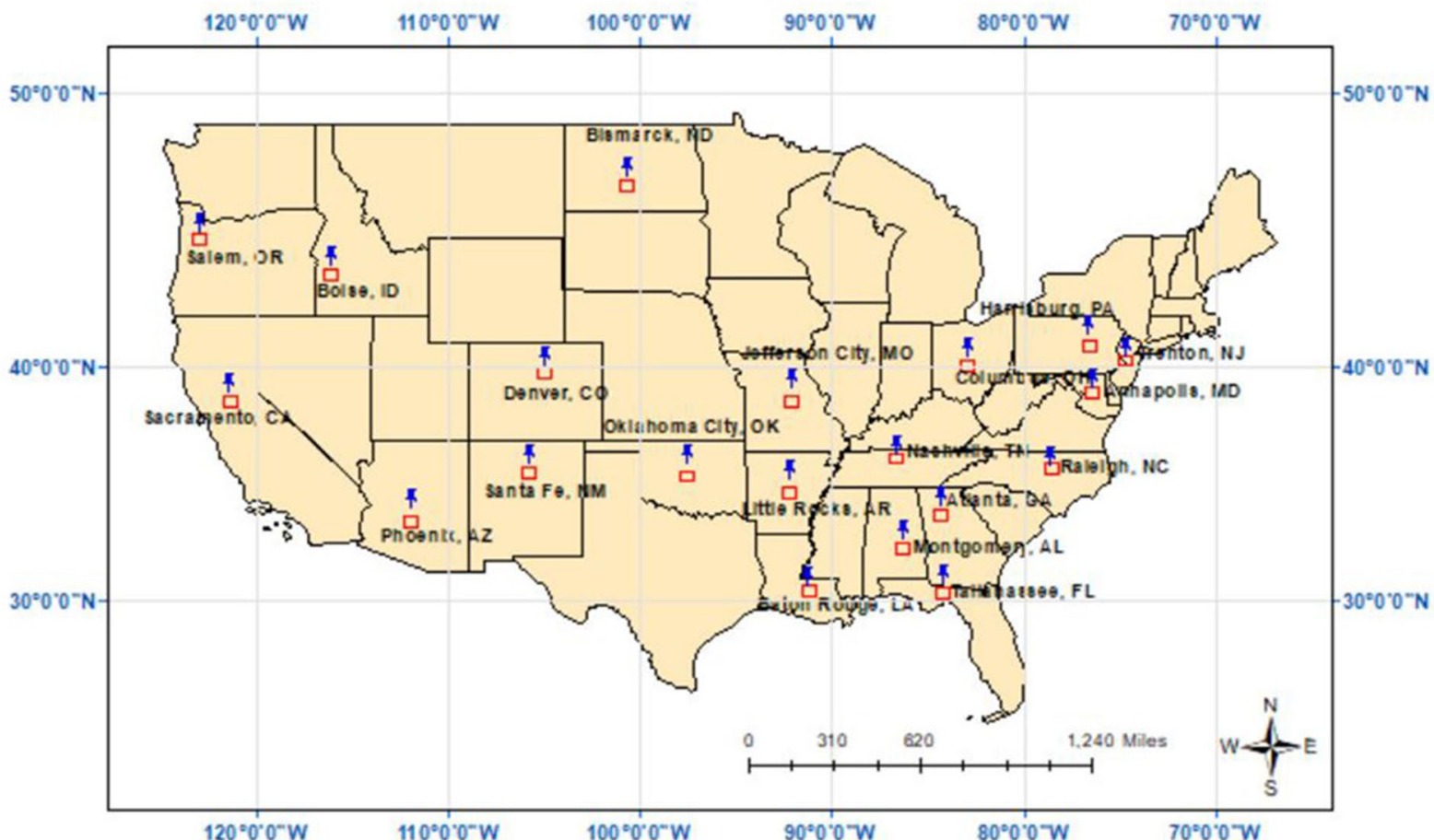

Fig. 1 a Spatial distribution of confirmed death due to COVID-19 until 19 March 2021. The maximum death occurred in US, but all the countries were affected. $\mathbf{b}$ Location of US EPA site of the measurement of $\mathrm{PM}_{2.5}$ 
lockdown partially and completely (Chauhan and Singh 2020, 2021; Wang et al. 2020) to minimize the spread of the COVID-19 virus. In India, a complete lockdown was observed by the Government, all the highways, education institutes, major industries, and private companies were closed. The complete lockdown helped in controlling the spread of the COVID-19 that improved the air quality, although with the complete lockdown, poor people suffered greatly and migrated people living in the major cities returned to their villages especially in India. People lost their jobs with such decision though, but they were happy to meet their family members in this pandemic.

In the US, COVID-19 severely affected the major population. About 562,526 people were demised and 30,962,803 people were infected with COVID-19 (https://www.world ometers.info/coronavirus/country/us/; Accessed on 16 March 2021). In some of the major cities such as New York, a large population was badly affected due to the COVID19. In the beginning, people who were using masks were considered a stranger and, in the US, people were moving freely without any mask. Even beaches were open, and, on some days, beaches were overcrowded. With the growing COVID-19 cases, some of the states have issued advisories to the people to stay home and keep social distancing. It has been observed that people have followed the social distancing regulations in some states, whereas in others the regulations were not heeded. Even in China, travel and movement restrictions were strictly followed which has helped to reduce the spread of the COVID-19 in the early months of the outbreak especially due to international travel (Chinazzi et al. 2020). Kraemer et al. (2020) found that human mobility was reduced that helped in the early outbreak of COVID-19 spread. The COVID-19 lockdown shows a positive effect on air quality mainly due to the movement of vehicles as some of the local companies initiated work from home orders. In the northwestern US, Seattle city was among the few cities which were affected by COVID-19 in the beginning, some of the IT companies asked their employees to work from home that helped to reduce the traffic.

Recently, Elshorbany et al. (2021) studied the impacts of the pandemic-related lockdown on air quality in the US using remote sensing products for tropospheric column nitrogen dioxide $\left(\mathrm{NO}_{2}\right)$, atmospheric column carbon monoxide (CO), tropospheric column ozone $\left(\mathrm{O}_{3}\right)$, and aerosol optical depth (AOD). They focused only on five major cities, New York (NY), Illinois (IL), Florida (FL), Texas (TX), and California (CA). They found improvements in air quality associated with the traffic volume in these cities in 2020 compared to the average values for the periods 2015-2019. Acharya et al. (2021) found pronounced changes in aerosol optical depth, tropospheric column density of $\mathrm{NO}_{2}$ and $\mathrm{SO}_{2}$ from satellite observations during lockdown periods
(2020) compared to earlier years in India, Europe, and the US. Blumberg (2020) found a 30\% drop in air pollution in the northeast US region during COVID-19. Berman and Ebisu (2020) found the real-time impact of the COVID-19 pandemic on measured U.S. air pollution using the federal air monitoring network. They found a sharp decrease in fine particulate matter $\left(\mathrm{PM}_{2.5}\right)$ and $\mathrm{NO}_{2}$ during the COVID-19 pandemic January 8-April 21, 2020, associated with the decline in traffic and restriction in business closures. Few studies were carried out using ground and satellite data for limited periods during COVID-19 and found improvement in air pollution with the reduction in traffic in the US (Burke et al. 2020; Chakrabarty et al. 2021; Chen et al. 2020; Xiang et al. 2020; Zangari et al. 2020).

We have analyzed various atmospheric parameters over 19 capital cities of the US states (covering major parts of the US) during the COVID-19 lockdown. We have carried out an analysis of the various atmospheric parameter derived from the MODIS Terra, Aqua, and AIRS satellites from January to June 2020 and compared these data with the same period from 2017 to 2019 . The analysis is covering major capital cities of the US (19 cities) for the analysis of AOD, $\mathrm{NO}_{2}$, Ozone, $\mathrm{PM}_{2.5}$, and $\mathrm{SO}_{2}$. As in the US, the lockdown period was not uniform, and the policies of the different states were different. So, it was required to analyze the change on monthly basis with broad spatial coverage which was still missing with other analyses done by previous researchers. The analysis suggested a decline in AOD and $\mathrm{NO}_{2}$ which can be since some of the US's capitals have strictly followed social distancing and some of the states ignored it and as a result, the COVID-19 cases have surged in many cities. We have studied $\mathrm{PM}_{2.5}$ using the published data from the Environmental Protection Agency (EPA) and the total column of ozone from OMI satellite data available through the NASA Giovanni portal.

\section{Data used}

For the current study, we have used various satellite, remote sensing, and ground observation data. The details of the data used have been provided here.

\section{Mobility data}

In the current study, we have used the mobility data provided by Google in Google Community Mobility Reports. The datasets are later averaged and plotted using ArcGIS Pro and it is available at https://www.google.com/covid19/mobility. 


\section{MODIS data}

MODIS or Moderate Resolution Imaging Spectroradiometer is one of the main instruments aboard the Terra and Aqua satellites. These satellite missions provide information on atmospheric aerosols and other remote sensing datasets. We have carried out the analysis of aerosol optical depth (AOD) using Aqua and Terra MODIS datasets and we take the average of these datasets. The spatial resolution of the datasets is $1^{\circ} \times 1^{\circ}$. The datasets are downloaded through the NASA Giovanni portal (https://giovanni.gsfc.nasa.gov/giovanni/) for detailed analysis of various cities in US.

\section{Rainfall data}

The rainfall data analysis for 2017-2020 was carried out with the NASA Global Precipitation Measurement (GPM) product. The Multi-Satellite Retrievals for GPM (IMERG) algorithm uses a multi-satellite precipitation dataset across the world. We have used the latest Version 6 datasets with spatial resolution $0.1^{\circ} \times 0.1^{\circ}$, which were downloaded through NASA Giovanni for the US region.

\section{OMI data}

The Ozone Monitoring Instrument (OMI) is part of the NASA Aura A-train satellite mission and provided the concentration of various atmospheric trace gases along with the atmospheric aerosols at different wavelengths. We have carried out the analysis of tropospheric $\mathrm{NO}_{2}$ and Ozone using OMI data. The temporal resolution of these datasets is 1 day, and the spatial resolution is $0.25^{\circ} \times 0.25^{\circ}$. We have downloaded the data using the NASA Giovanni portal for the long time series of the $\mathrm{NO}_{2}$ and Ozone,

\section{AIRS data}

We have carried out the analysis of surface temperature over the US for the periods January-June 2020 using Atmospheric Infrared Sounder (AIRS) satellite datasets. AIRS satellite is part of NASA A-train satellite mission, measures various meteorological parameters and trace gases concentration in the vertical column of atmosphere. For our analysis, we have used the average of ascending mode (daytime) and descending mode (nighttime) data over the whole area of interest for better temporal coverage.

\section{Air quality data}

The air quality is monitored in every country throughout the world. The concentration of Particulate matter is the best indicator of air quality. The higher $\mathrm{PM}_{2.5}$ concentration affects
Table 1 Locations of US EPA stations

\begin{tabular}{|c|c|c|c|c|c|}
\hline S. No. & Capit & West & South & East & Nor \\
\hline 1 & Mont & -86 & 25 & -86.07 & 32. \\
\hline 2 & Pho & 46 & 33.26 & - & 33.6 \\
\hline 3 & Litt & -5 & 53 & & 34.8 \\
\hline 4 & California & -12 & 38.44 & -1 & 38.6 \\
\hline 5 & Den & 11 & 39.61 & 60 & 39.9 \\
\hline 6 & ee, Flor & -8 & 30.35 & - & 30.5 \\
\hline 7 & Atlan & -8 & 33.65 & $-\varepsilon$ & 33.8 \\
\hline 8 & Boise, I & -116.37 & 43.51 & -11 & 43.65 \\
\hline 9 & uge, Lor & -91 & 30.34 & -9 & 30.5 \\
\hline 10 & Ann & -7 & 38 & -7 & 39.0 \\
\hline 11 & Jeffe & -92 & 38.52 & -9 & 38.62 \\
\hline 12 & Tren & -74 & 40.18 & -7 & 40.2 \\
\hline 13 & Santa Fe, New Mexico & -106.11 & 35.59 & -1 & 35.7 \\
\hline 14 & Raleigh, North Carolina & -78.82 & 35.71 & -78 & $35.9^{7}$ \\
\hline 15 & , North & -100.85 & 46.75 & .69 & 46.8 \\
\hline 16 & Columbus, Ohio & -83.21 & 39.81 & -8 & 40.1 \\
\hline 17 & $\begin{array}{l}\text { Oklahoma City, Okla- } \\
\text { homa }\end{array}$ & -97.83 & 35.29 & -97.12 & 35.6 \\
\hline 18 & egon & -12 & 44.85 & -12 & 45.0 \\
\hline 19 & burg, Pennsyl- & -76.92 & 40.24 & -76.84 & 40.3 \\
\hline 20 & Nashville, Tennessee & -87.05 & 35.97 & -8 & 36.4 \\
\hline
\end{tabular}

human health, especially the respiratory system. We have analyzed $\mathrm{PM}_{2.5}$ concentration over various locations in US Capital cities using US EPA datasets (https://www.epa.gov/ outdoor-air-quality-data/download-daily-data). The coordinate of these locations (Fig. 1b) is provided in Table 1.

\section{Results and discussion}

Traffic emissions are a primary source of carbon monoxide $(\mathrm{CO})$, nitrogen oxide $(\mathrm{NO})$, and nitrogen dioxide $\left(\mathrm{NO}_{2}\right)$. While $\mathrm{CO}$ and $\mathrm{NO}$ are emitted directly from vehicle emissions, $\mathrm{NO}_{2}$, Ozone $\left(\mathrm{O}_{3}\right)$, and secondary organic and inorganic aerosols are mainly photochemical products, and their atmospheric concentration and lifetime depend on the nonlinear chemistry of $\mathrm{O}_{3}, \mathrm{NOx}\left(\mathrm{NOx}=\mathrm{NO}+\mathrm{NO}_{2}\right)$, and volatile organic compounds (VOCs) in addition to the oxidant's levels, meteorology, and solar radiation. For our analysis, we have used various remote sensing datasets.

\section{Meteorological analysis}

In Fig. 2, we have shown the spatial variation of monthly mean surface temperature for (a) 2017-2019 and (b) 2020. During January-March, the temperature of the study 

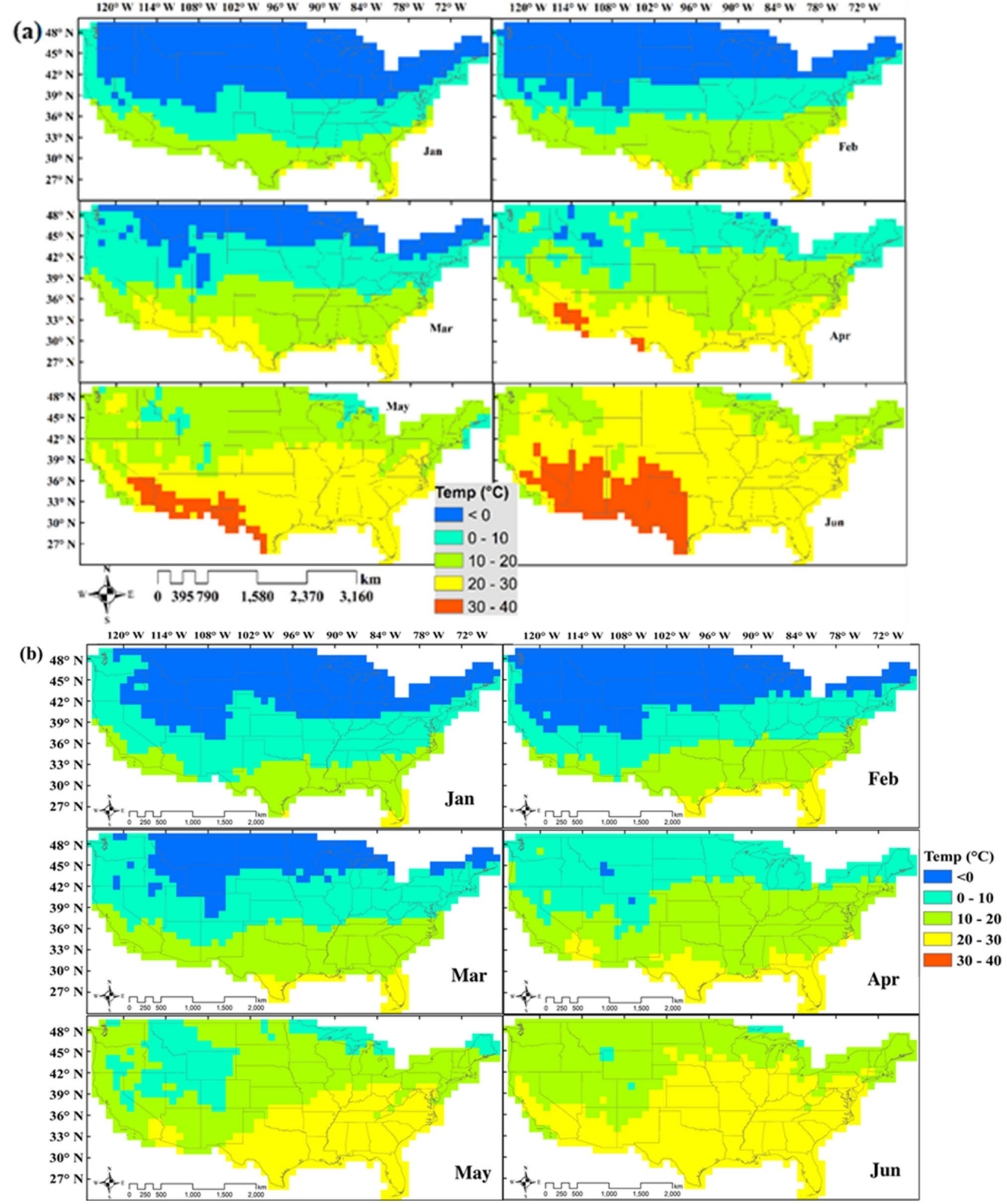

Fig. 2 The monthly mean Surface temperature during January-June a 2017-2019 and b 2020 


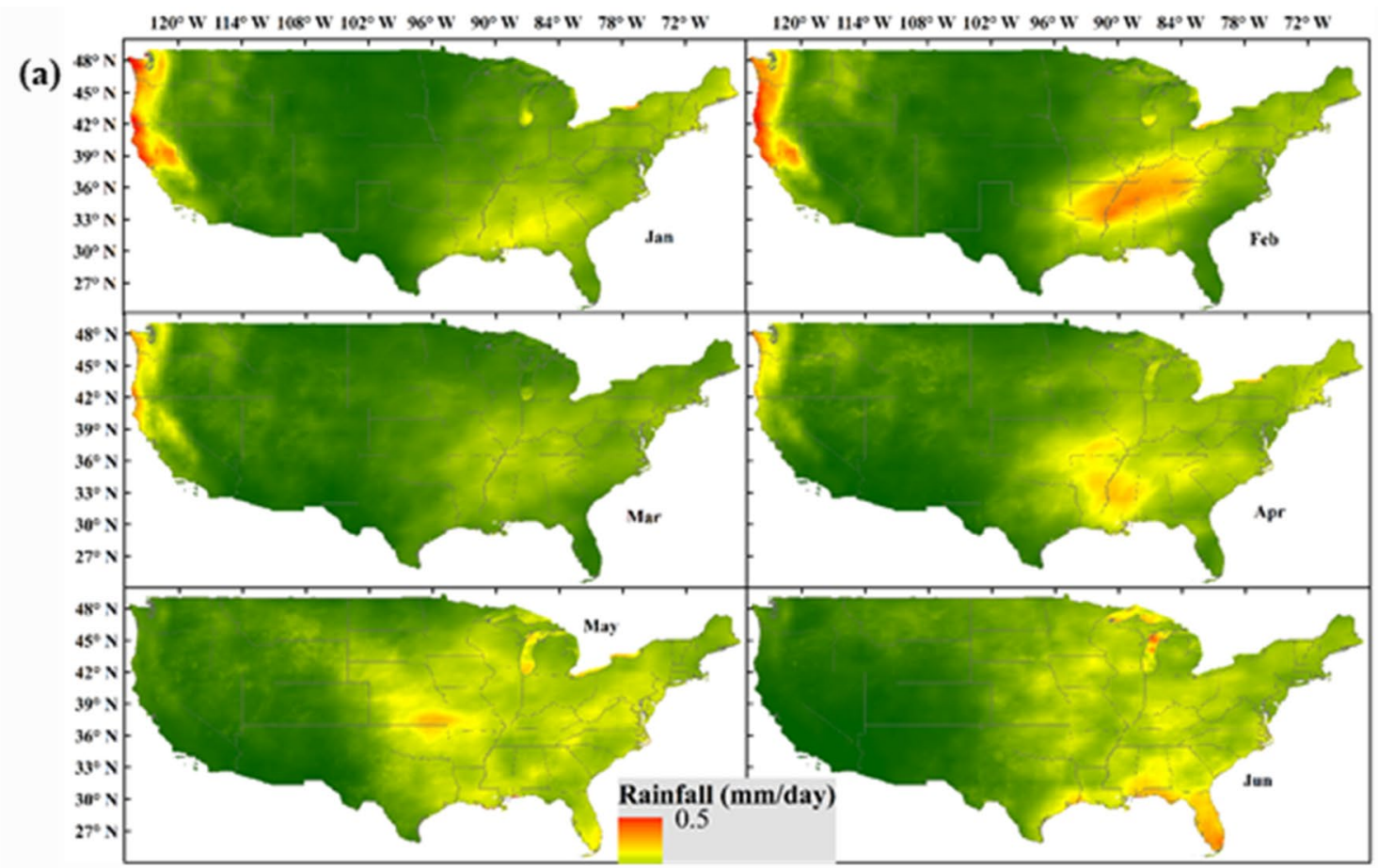

(b)

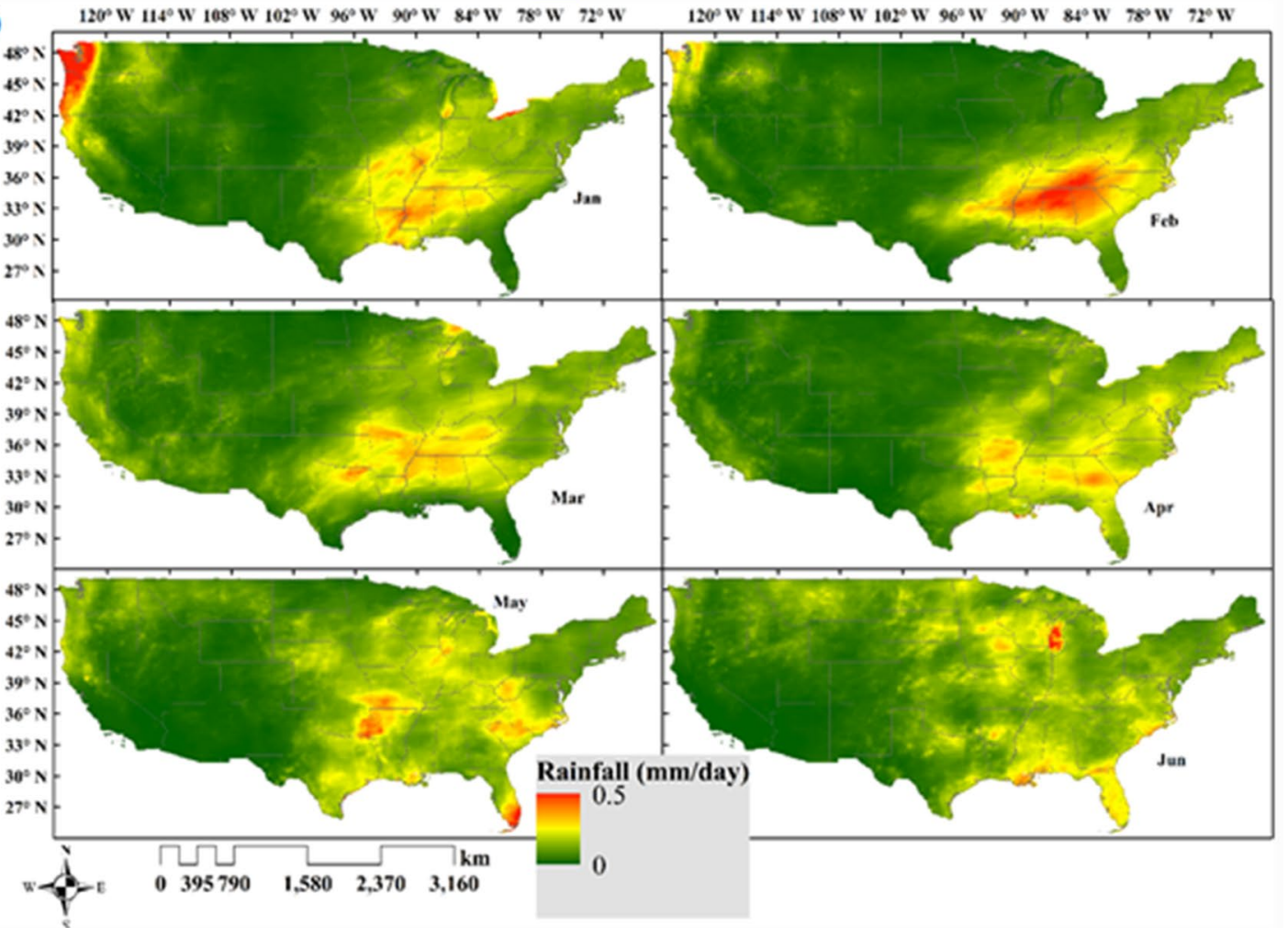

Fig. 3 The monthly mean rainfall during January-June a 2017-2019 and b 2020

region lies between below zero and $30{ }^{\circ} \mathrm{C}$. The mean monthly temperature falls below $0{ }^{\circ} \mathrm{C}$ mostly in the region covering $39^{\circ}-51^{\circ} \mathrm{N}$ of the US during January-March. The temperature rises in the months April-June. The temperature of the south-western part of the US lies between 20 and $30{ }^{\circ} \mathrm{C}$ during January, May, and June months. On 
comparing both years (Fig. 2a and Fig. 2b), no major changes are observed till April but in 2020, the surface temperature varies in the range $30-40{ }^{\circ} \mathrm{C}$. In Fig. 3, we have shown the spatial variation of monthly mean rainfall for (a) 2017-2019 and (b) 2020. The total rainfall during 2020 is a bit higher side in respect to the average value from 2017 to 2019. But significant fall in rainfall is seen over the western parts during 2020 yet rise is seen in the eastern and central parts of USA.

\section{Impact of lockdown on human activities}

Further, we have considered the average google mobility data for each month for different states. For representation purposes, we have used a different set of colors based on the average mobility of the state. In Fig. 4, we have shown the average monthly mobility (corresponds to median values) over the USA. A sharp decline in mobility is observed during 2020. During January 2020, the mobility in major states declines up to $12-14 \%$. In Feb, an increase in mobility is observed compared to January, still shows a fall up to $3-12 \%$. Similarly, the rise is observed in the major states during March, but a sudden drop is observed in the month of April up to $15 \%$ mobility across the whole study area which remains lower in the month May 2020, but in some states, an increase in mobility is observed in the month of June at Washington, Oregon, Michigan, Ohio, Pennsylvania, New Jersey, Maine, and other northeastern states. These data show a higher degree of agreement with the COVID-19 spread in the US. The cases of COVID-19 were suddenly increased in the US in the month of April, some states imposed the partial lockdown and strictly implemented social distancing rules to stop the spread.

\section{Variations in aerosols optical depth}

AOD variability depends on various atmospheric and meteorological parameters, season, local source, and long-range transportation. We have carried out the monthly mean analysis of AOD for 19 capital cities of US states for January-June from 2019 to 2020 . Figure 5a shows the variation of monthly mean AOD during 2019-2020 with color represents index AOD ranges. The highest monthly mean AOD was 0.72 in the month of June 2019 and 0.43 in the month of June 2020 for Missouri. AOD values are lower during January-February and later some rise is observed in monthly mean values. During 2020, the color contrast is lower for the winter to summer months in comparison to 2019 (Fig. 5a).

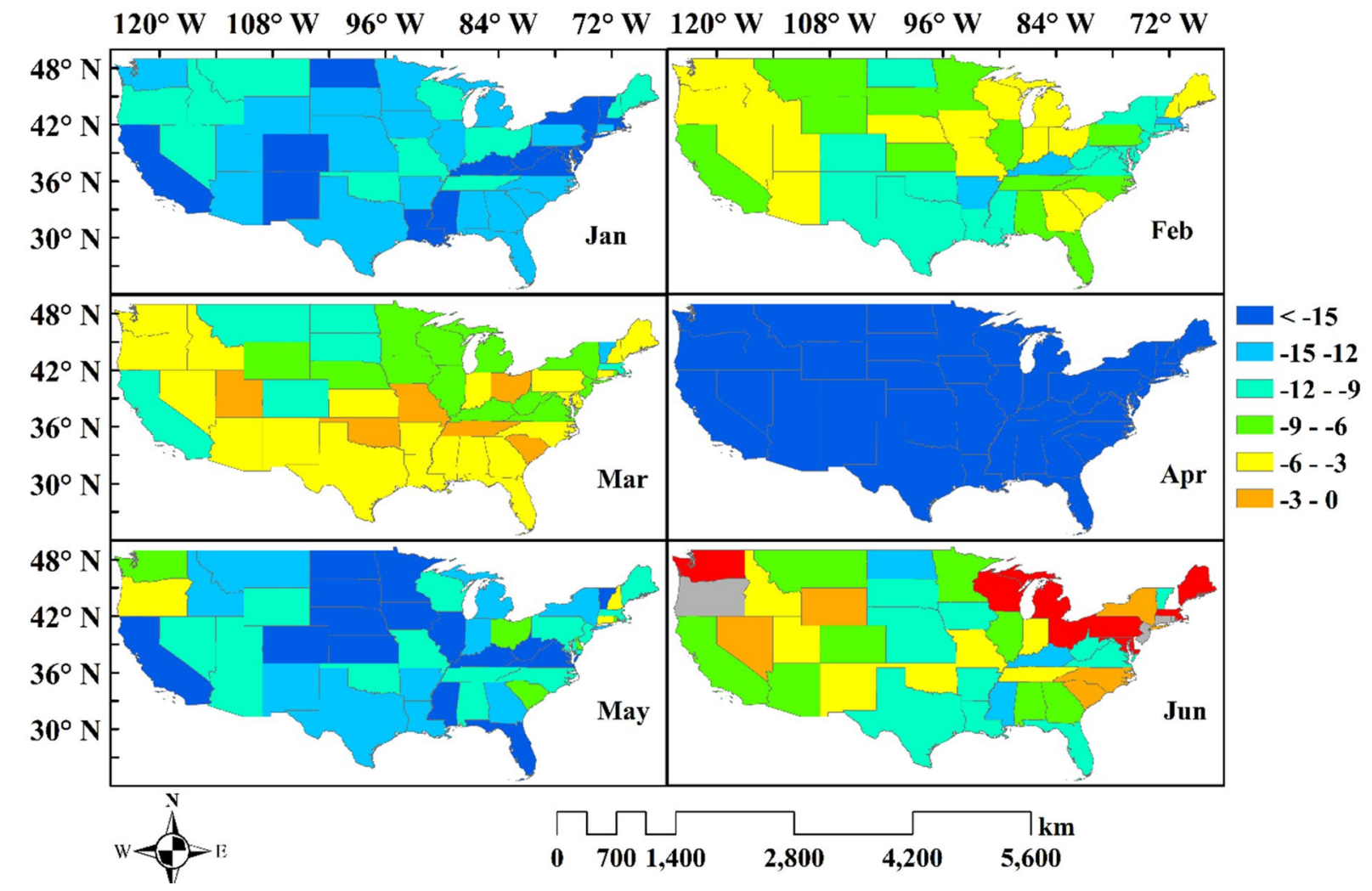

Fig. 4 The monthly average mobility (corresponds to the median values) of US during January-June 2020 


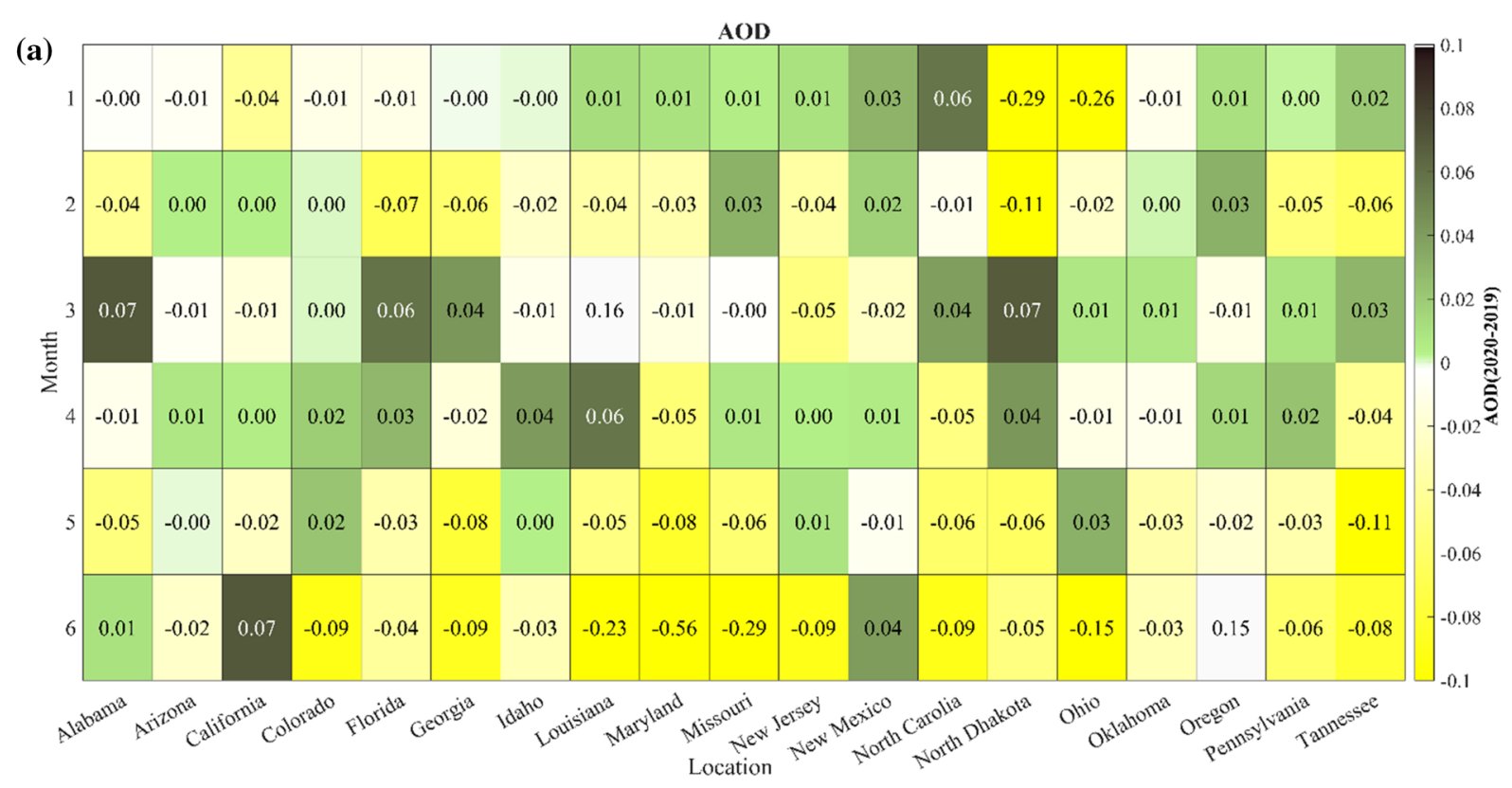

(b) $\quad 120^{\circ} \mathrm{W} \quad 114^{\circ} \mathrm{W} \quad 108^{\circ} \mathrm{W} \quad 102^{\circ} \mathrm{W} \quad 96^{\circ} \mathrm{W} \quad 90^{\circ} \mathrm{W} \quad 84^{\circ} \mathrm{W} \quad 78^{\circ} \mathrm{W} \quad 72^{\circ} \mathrm{W} \quad 420^{\circ} \mathrm{W} \quad 114^{\circ} \mathrm{W} \quad 108^{\circ} \mathrm{W} \quad 102^{\circ} \mathrm{W} \quad 96^{\circ} \mathrm{W} \quad 90^{\circ} \mathrm{W} \quad 84^{\circ} \mathrm{W} \quad 78^{\circ} \mathrm{W} \quad 72^{\circ} \mathrm{W}$

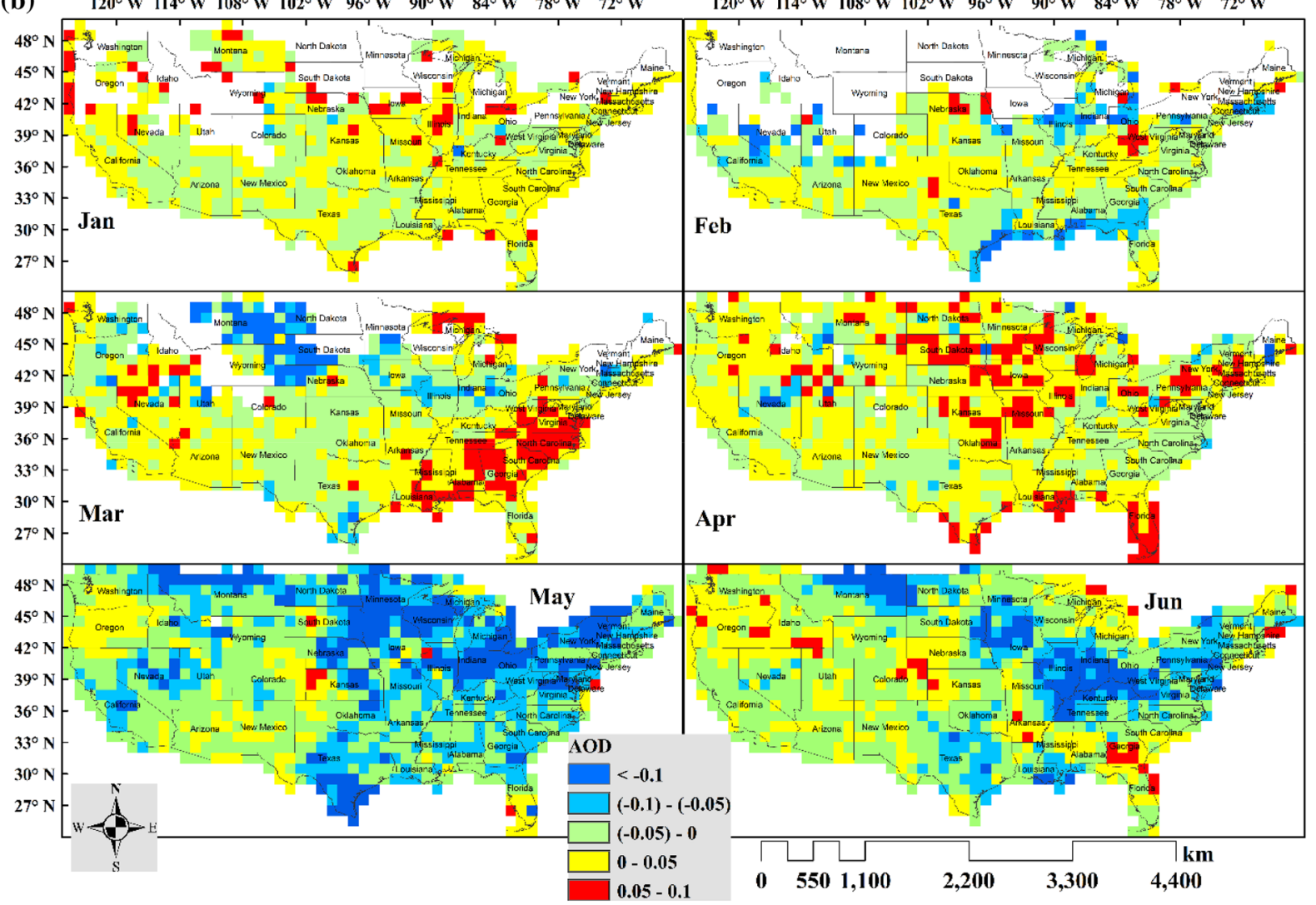

Fig. 5 a Difference (2020-2019) in monthly mean AOD concentration in US states during January-June. b Difference (2020-2019) in spatial variations of AOD over US during January-June. c Spatial variation of AOD. The left-side images show each month's average values for 2017-2019, whereas the right-side images show the monthly mean values during 2020 


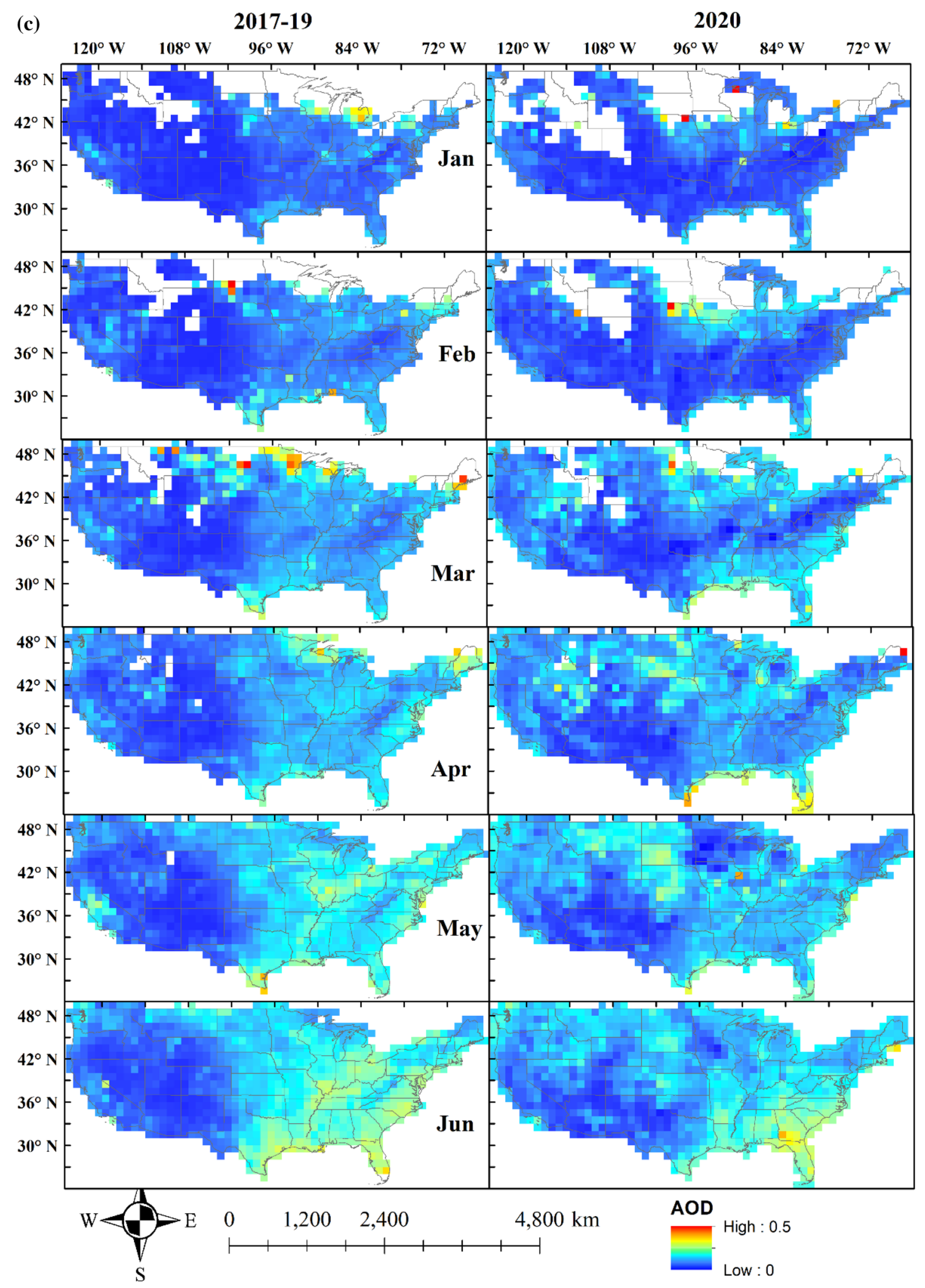

Fig. 5 (continued) 
We have also carried out the spatial analysis of the difference in AOD values over the US during 2020. For this, first, we have averaged the morning and afternoon time AOD values over the whole US (average of Terra and Aqua MODIS data) and then taken the difference for the periods 2019 and 2020 to find the changes at the time of COVID-2020 (Fig. 5b). The values more than 0 show that there is a rise in AOD during 2020 and the region with AOD less than 0, shows a decline in AOD during 2020. During January 2020, the AOD values are higher in Southern, Central, and Eastern States compared to 2019. During February 2020, the higher values shift towards the western and south-western parts of the US along with the central parts. During March, a significant rise in AOD values is observed (more than 0.1) in eastern to south-eastern parts of the USA, and a rise of more than 0.5 is observed in the western states of the USA. No major data points are available in the Northern parts of the US from January to February.

In the northern parts, a pronounced decline in AOD values is observed in the month of March 2020 in comparison to 2019. Similarly, increase in AOD shifts from the lower half of the US to the upper half in the month of April 2020. But we found a pronounced fall (less than 0 and 0.5 ) during May 2020 which was the peak time of the spread of the COVID-19 in the USA and lower AOD was observed in June 2020 compared to 2019, but this was higher than May 2020 and this observation is supported from the mobility data of US, mobility shows an increase in June. Hence the lockdown in the USA affected the AOD concentration in 2020. On comparing the data of 2019 and 2020, we have also seen that the AOD values are relatively lower during 2020. Louisiana, Maryland, Missouri, North Carolina, and North Dakota show a decline in the overall AOD during 2020 to large extent. For long-term analysis, we have also compared the monthly mean AOD values average for 2017-2019 and 2020 (Fig. 5c). In comparison to the mean values of 2017-2019, we found decline in AOD values in the Central, Eastern, and Southern parts of the US from March to June 2020. But in the Northern and western parts of the US, the AOD values remained higher in 2020 compared to long-term average.

\section{Change in air quality}

We further investigated the changes in $\mathrm{PM}_{2.5}$ concentration at various capital cities of major US states as the impact of lockdown is directly impacted the particulate matter concentration in various parts of the world and well reported for India, China, and Europe. This time, we have carried out the analysis of changes in $\mathrm{PM}_{2.5}$ concentration prior, and after the COVID-19. As in the US, few states have imposed the partial lockdown, but many people moved from one city to other cities during the shutdown of offices, educational institutions, and industries.

Later, due to the sudden rise in COVID-19 cases in the USA, major populations started following the social distancing rules along with the effective lockdown. In Fig. 6, we have shown the changes in the monthly mean $\mathrm{PM}_{2.5}$ concentration over nineteen cities of the US. The positive shifts show the increase in $\mathrm{PM}_{2.5}$ concentration during 2020 whereas the negative shifts show the decline in the concentration of $\mathrm{PM}_{2.5}$ during 2020. First, the negative shifts are statistically higher than the positive shift in most of the states. During the whole study period, we found an overall

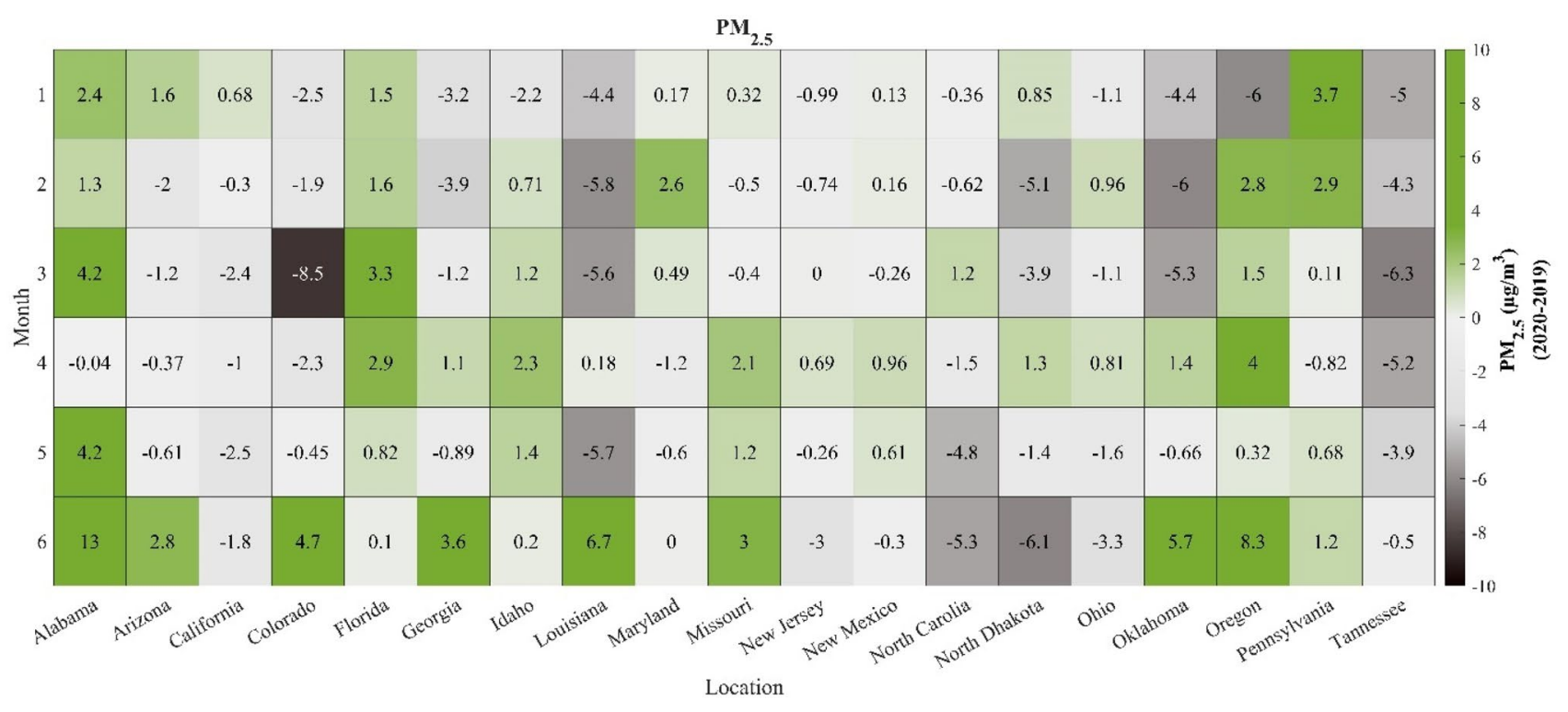

Fig. 6 Difference (2020-2019) in monthly mean PM2.5 concentration in US states during January-June 
decline until May, and afterward, a rise is seen in June 2020. The lockdown in the US is implemented in various stages means some state follows in a major way, whereas some states implemented partially. In Alabama, the negative shifts are seen in April only. Arizona, Colorado, Georgia,
Louisiana, Maryland, New Jersey, North Carolina, North Dakota, Ohio, and Tennessee show a negative shift during April and May, that show decline in the $\mathrm{PM}_{2.5}$ concentration at these locations during 2020. Alabama, Florida, Idaho, Missouri, and Oregon have shown no decline in

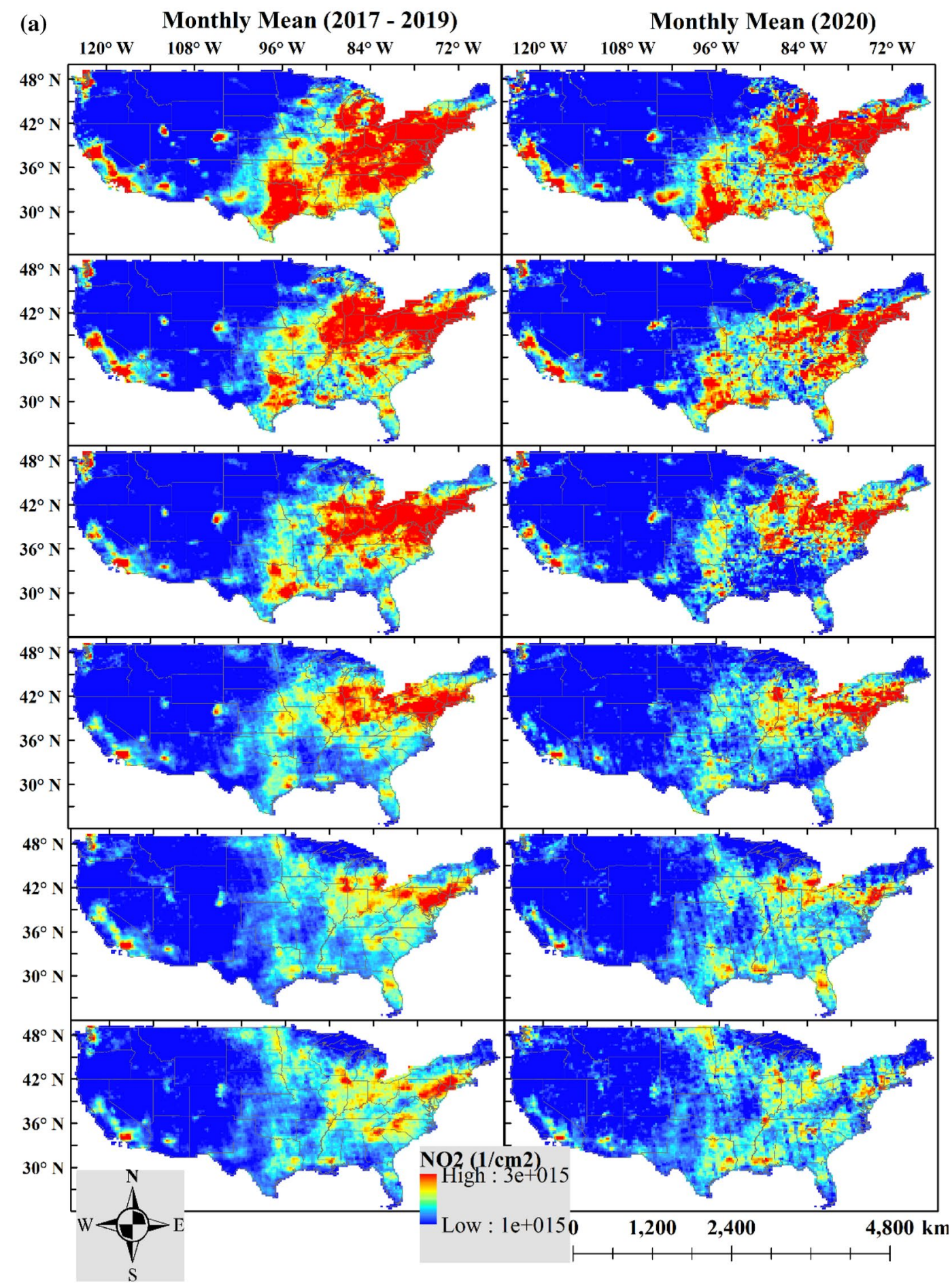

Fig. 7 a Spatial variations of $\mathrm{NO}_{2}$ over USA. The left-side images show average of each monh for 2017-2019, whereas the right-side images show the monthly mean values during 2020. b Difference in monthly mean $\mathrm{NO}_{2}$ concentration over different US states during January-June 2020 


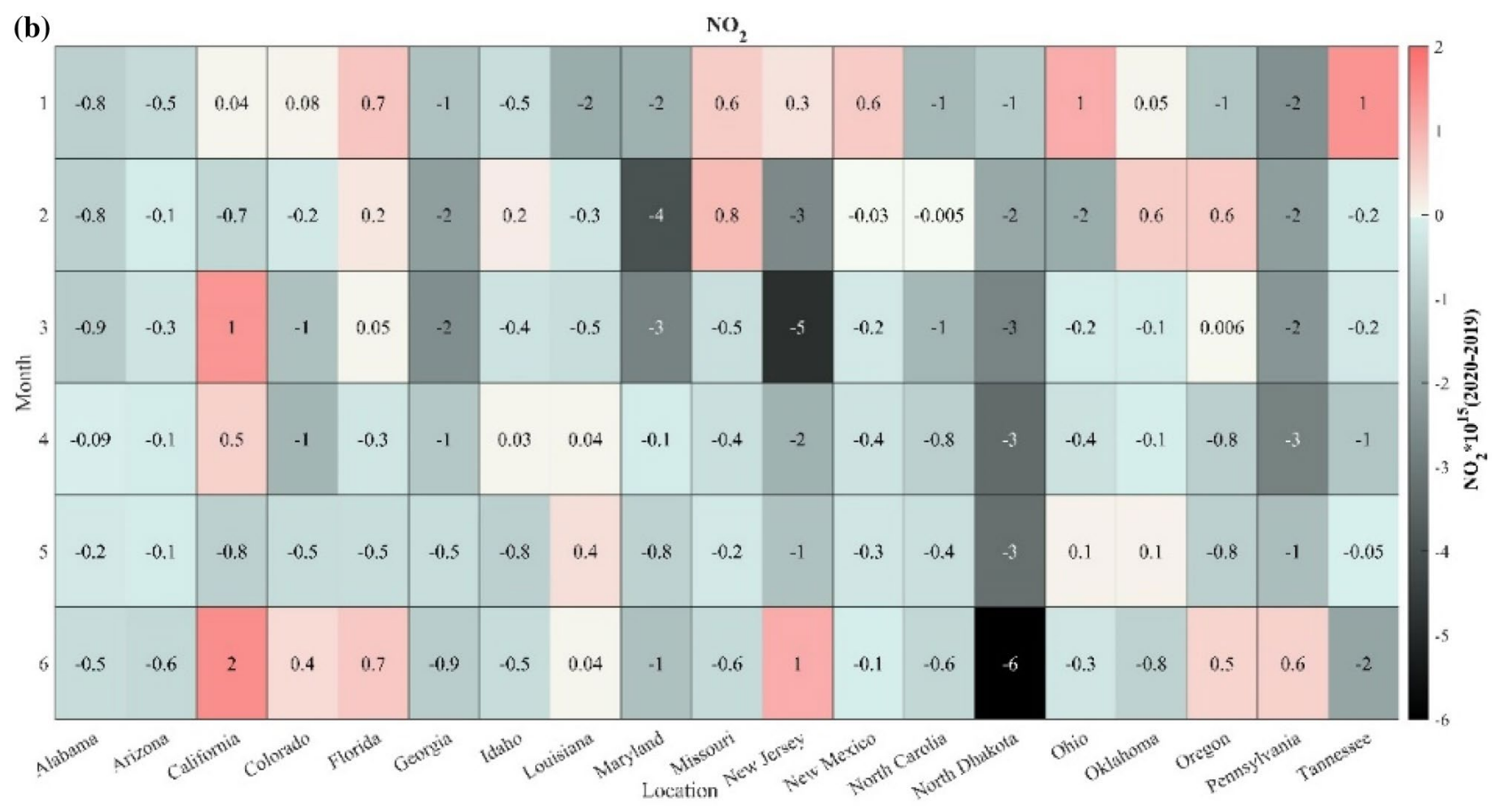

Fig. 7 (continued)

$\mathrm{PM}_{2.5}$ concentration. California and Tennessee have shown a regular decline in $\mathrm{PM}_{2.5}$ concentration during 2020 compared to 2019. Other locations show mixed changes in $\mathrm{PM}_{2.5}$ concentration due to various lockdown policies in various states. The tropospheric $\mathrm{NO}_{2}$ is one of the short-lived gases and is considered as one of the key indicators for the local to regional air quality indicator. The changes in the tropospheric $\mathrm{NO}_{2}$ are shown in Fig. 7a and b. In Fig. 7a, we have shown the monthly mean $\mathrm{NO}_{2}$ concentration. The left plane of the image shows monthly mean values during each month and averaged for 2017-2019 and the right plane shows the monthly mean values during 2020. During January 2020, no major reduction is observed in tropospheric ozone concentration. During February, Kansas, Missouri, Alabama, and Georgia have undergone a significant reduction of $\mathrm{NO}_{2}$ concentration. During March and April, a significant fall is observed over major states of the US except for most eastern states. But during May and June, a significant fall in $\mathrm{NO}_{2}$ concentration is observed. For further analysis, we have calculated the average tropospheric $\mathrm{NO}_{2}$ concentrations over the individual state (Fig. 7b). In Fig. 7b, the difference between 2020 and 2019 is shown for individual cities. The changes show the reduction in $\mathrm{NO}_{2}$ concentration especially during March-May and these months, we found mostly the negative shifts (Fig. 7b). But these results are not comparable with the changes in $\mathrm{PM}_{2.5}$, as many locations show an overall decline in $\mathrm{NO}_{2}$ concentration, and the same location is not showing an overall decline in the $\mathrm{PM}_{2.5}$ concentrations. The concentration of particulate matter is not only affected by anthropogenic sources but also during hot weather, the concentration is also affected by various natural sources like dust. The monthly mobility and decline in tropospheric $\mathrm{NO}_{2}$ show a good relation.

\section{Variability of ozone and $\mathrm{SO}_{2}$}

In Fig. 8a, we have shown the total ozone column difference during 2020-2019 for each month January-June. The total ozone shows seasonal and latitudinal changes. During January month, we found an enhancement in the total ozone column over major parts of the US. In the northwestern parts, the ozone concentration is found to be higher in the range 60-90 DU, whereas in most of the regions, ozone concentration is found to be higher up to 60 DU. During February, we found a decline in ozone concentration in the northwestern regions over Washington state ( -30 to 0$)$, Oregon ( -30 to 0 ), Ohio ( -15 to 0 ), Nevada, California, Montana, and North Dakota. In other regions, we observe an increase of up to 60 DU, especially in the central and eastern states. During March, the change is found to be opposite from February, this time major fall in ozone concentration is observed. The eastern and northern regions show a decline ( -30 to 0$)$, which is also observed in the eastern regions of the US. During April, again the ozone concentration bounced back, and decline is observed in Texas, New Mexico, Arizona, and Washington states. Further, in May, a pronounced decline is observed. This time all the western, central, and most 


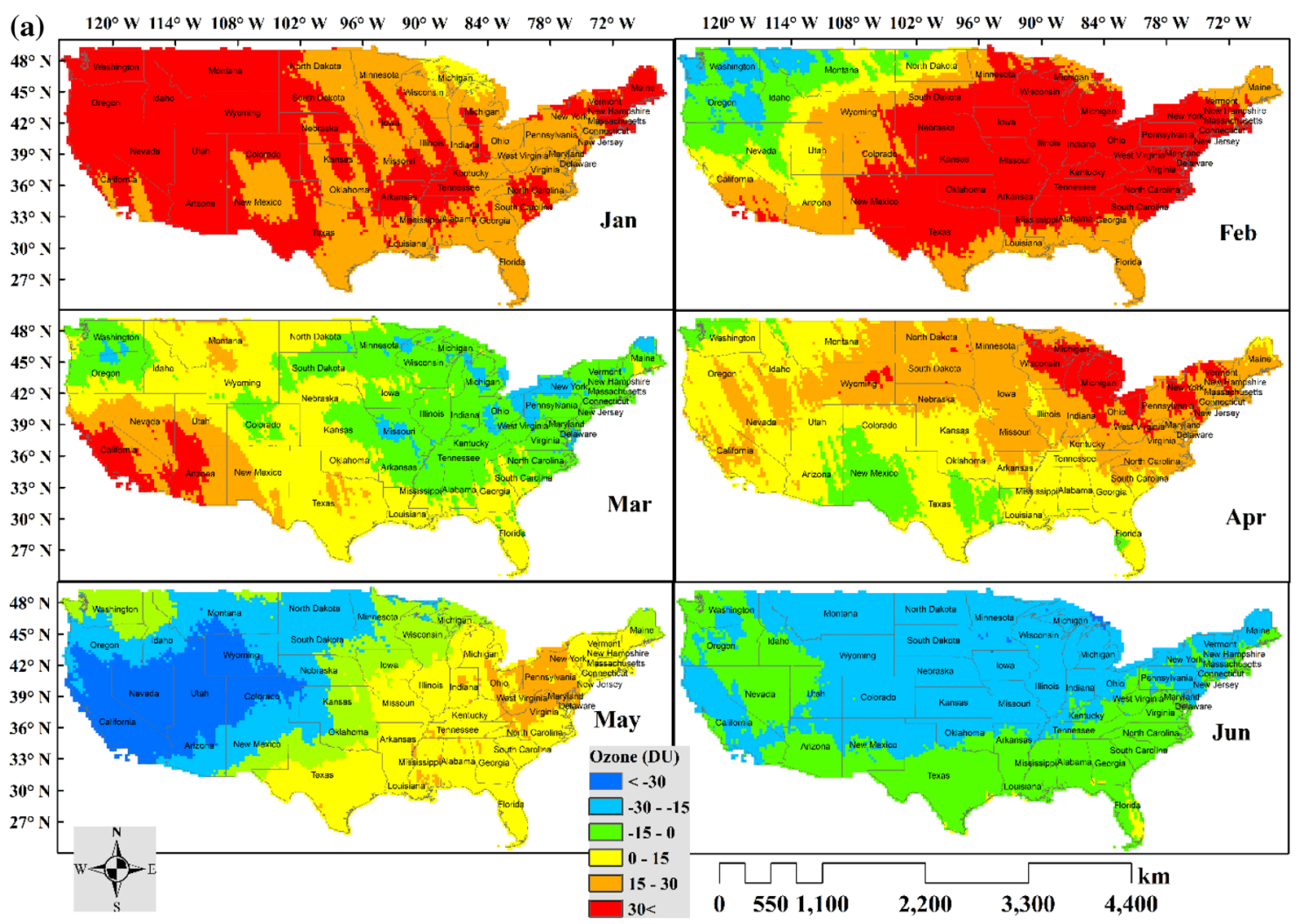

Fig. 8 a Difference (2020-2019) in spatial variations of Total Column Ozone over US during January-June. b Spatial variations of total column Ozone over USA. The left-side images show each month average values for 2017-2019, whereas the right-side images show

northern regions show a decline, an increase is seen in half of the eastern regions of the US. During June, we found a decline in Ozone concentration in large areas of the US.

This time, a small region of Florida shows an increase in Ozone concentration. The variability of ozone shows the same relationship with the average values of 2017-2019 (Fig. 8b) When we average total column ozone over various states, the results show quite an important pattern (Fig. 8c). The Ozone concentration (Fig. 8c) in all the cities remained quite similar during February except Idaho and Oregon. But we found a major decline in Ozone concentration during March which further recovered in April, and we found negative shifts for New Mexico in April. In May, many states show a negative shift, in June 2020, a sudden decline is observed in all the states except Florida and Louisiana. The decline in tropospheric $\mathrm{NO}_{2}$ concentration during May and June is related to a reduction in anthropogenic activities, and during this period $\mathrm{PM}_{2.5}$ increase due to dust pollution that decline the tropospheric ozone concentration in many major cities of US states.

We have also analyzed the variability of total column $\mathrm{SO}_{2}$ over the US. The spatial variations of $\mathrm{SO}_{2}$ are quite complex in comparison to total column ozone and the monthly mean values during 2020. c Difference (2020-2019) in monthly mean total Column Ozone over 19 different cities in US states during January-June 2020

tropospheric $\mathrm{NO}_{2}$. We have shown difference of monthly mean column $\mathrm{SO}_{2}$ (Fig. 9a). During January, central, northern and eastern regions show enhancement in total column $\mathrm{SO}_{2}$ during 2020 due to the positive shift (0-0.75 DU), whereas the negative shifts are also observed in some locations. In the western, northern, and southern regions, the variations are quite low. High and low shifts are observed in some regions. The pattern is almost similar in February. During March 2020, a decline in $\mathrm{SO}_{2}$ concentration is observed and the number of pixels with orange to red is lower in comparison to other pixels. From April to June, we found an increase in the negative shift over major parts of the US. On comparing the concentration of total column $\mathrm{SO}_{2}$ during 2020 with the monthly mean concentration during 2017-2019, we found increase in $\mathrm{SO}_{2}$ concentration from January to March 2020 but during April to June 2020, the western parts show an overall reduction, but the eastern states show a rise in monthly mean $\mathrm{SO}_{2}$ concentration. We did not find major changes in $\mathrm{SO}_{2}$ concentration during 2020 since major sources of $\mathrm{SO}_{2}$ in the US are Thermal power plants, Smelters, Gas, and Oil fields (Fioletov et al. 2016) which were not closed during lockdown periods. 


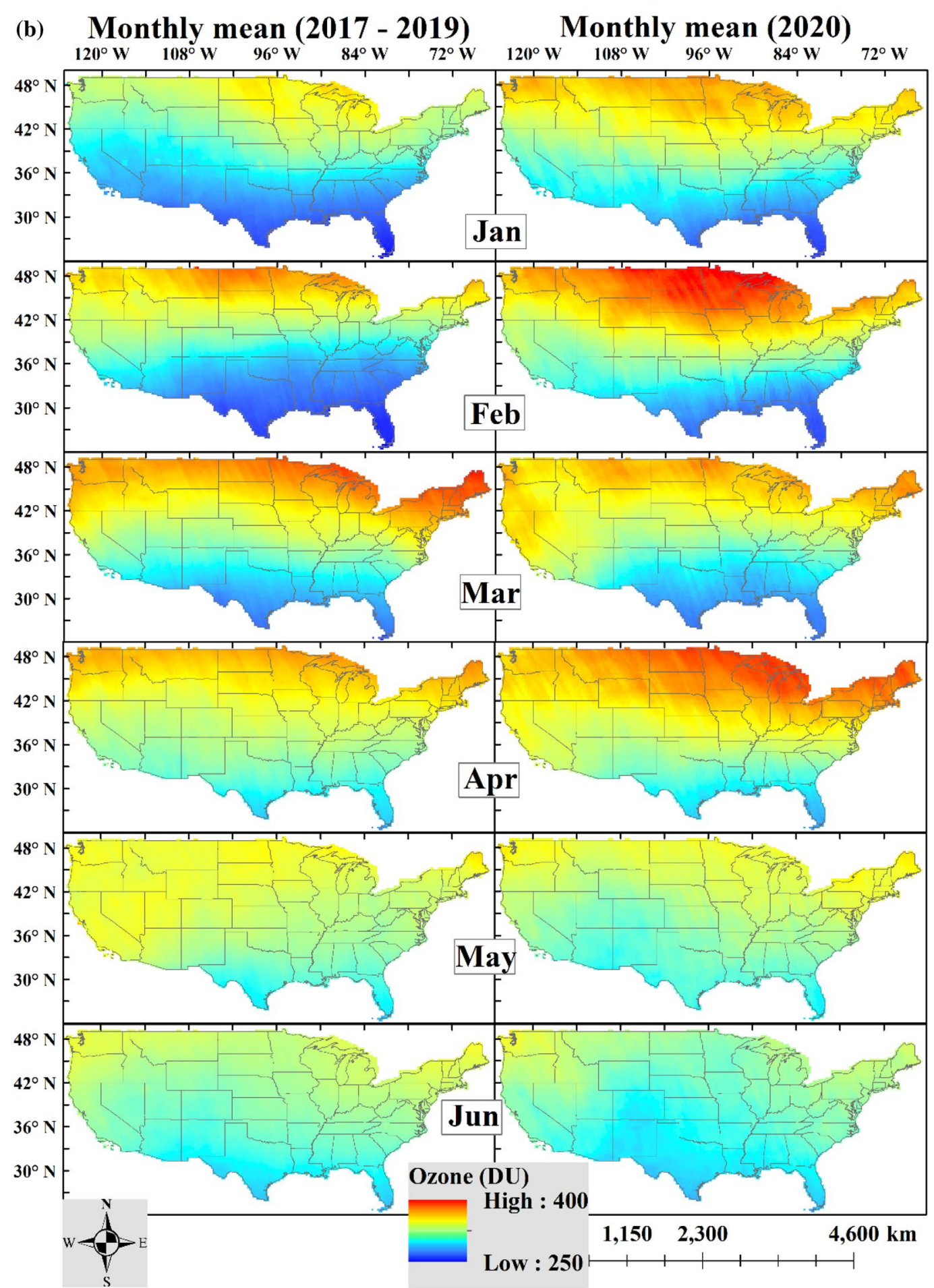

Fig. 8 (continued)

\section{Conclusion}

In this deadliest pandemic of twenty-first century COVID19 , a large number of people were killed and many of the families lost family member and lost their jobs across the globe and still, the spread is continuous. Now the world is seeing, second and third waves of this pandemic in some parts of the world. To stop the spread of the virus, lockdown and social distancing were followed by some of the countries as the first line of defense. India, China, and major European 


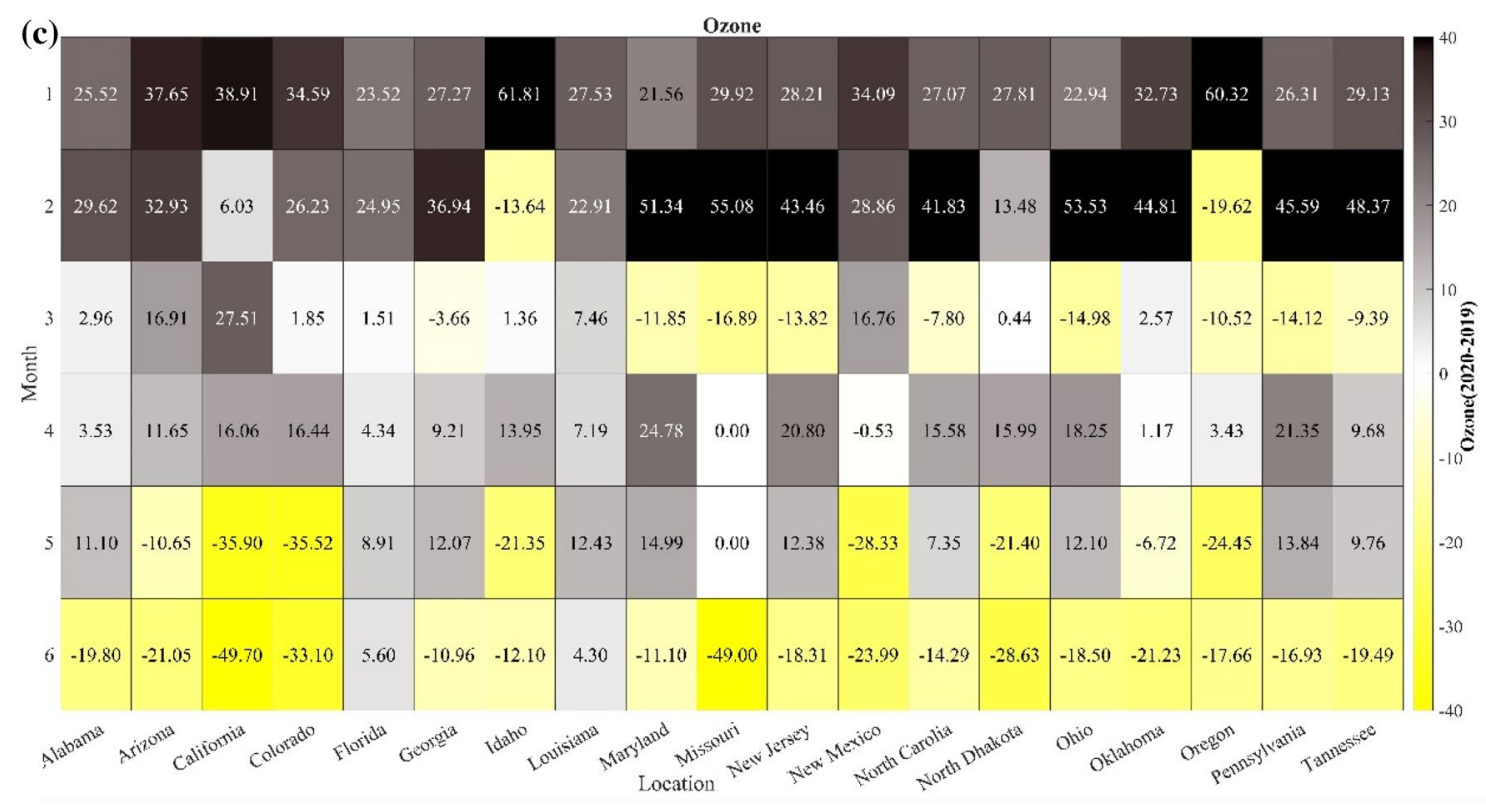

Fig. 8 (continued)

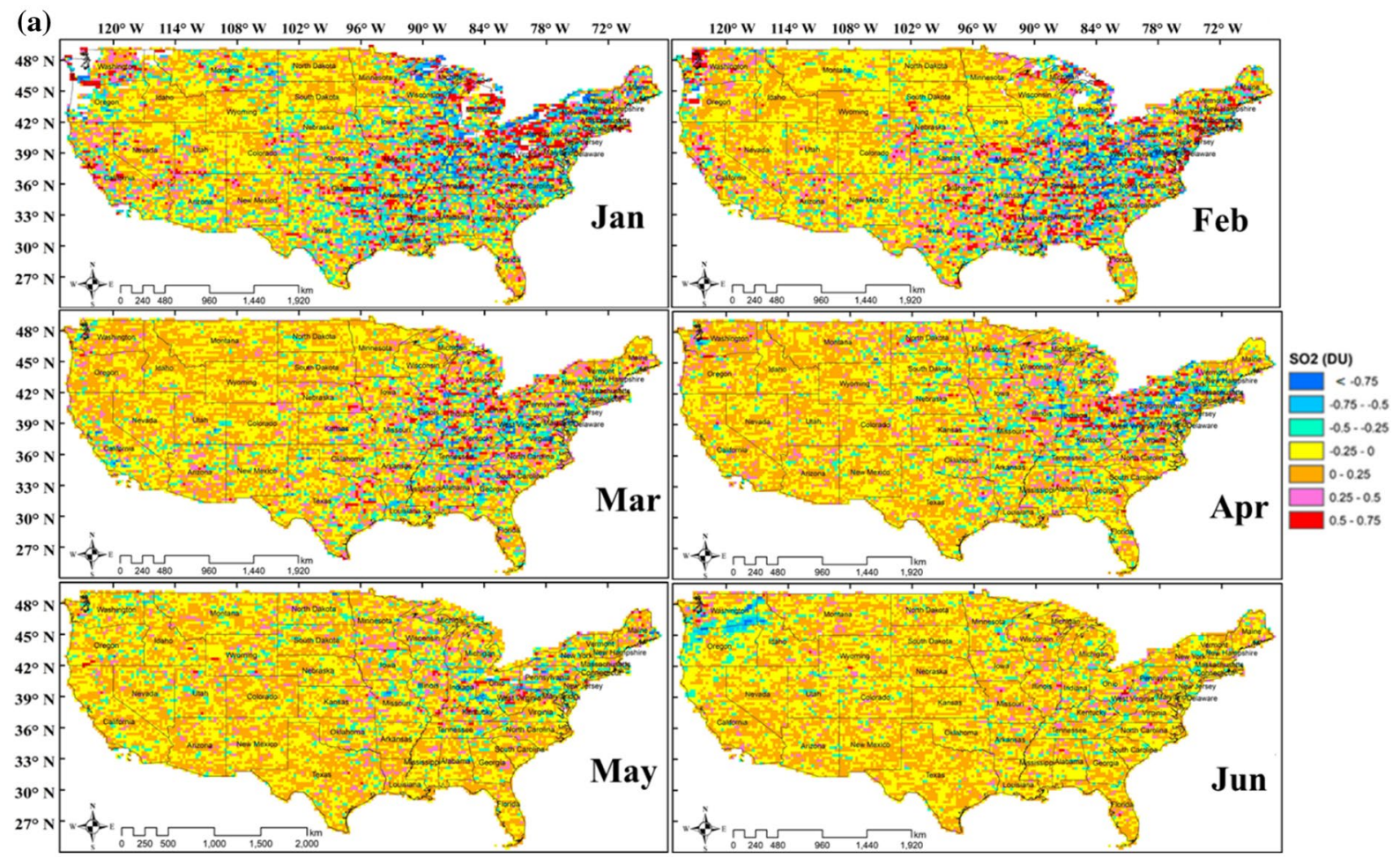

Fig. 9 a Difference in 2020-2019 in total column of $\mathrm{SO}_{2}$ over US during January-June. b Spatial variation of total column $\mathrm{SO}_{2}$ over USA. The left-side images show average values for each month dur-

countries followed strict lockdown and benefited from the improvement in air quality. In the US, the lockdown policies were not followed initially but with the rise in the number ing 2017-2019, whereas the right-side of images show the monthly mean values during 2020

of positive cases and death, the major population shows its concern. These changes are seen with the fall in mobility during April and May 2020. This affected the air quality 


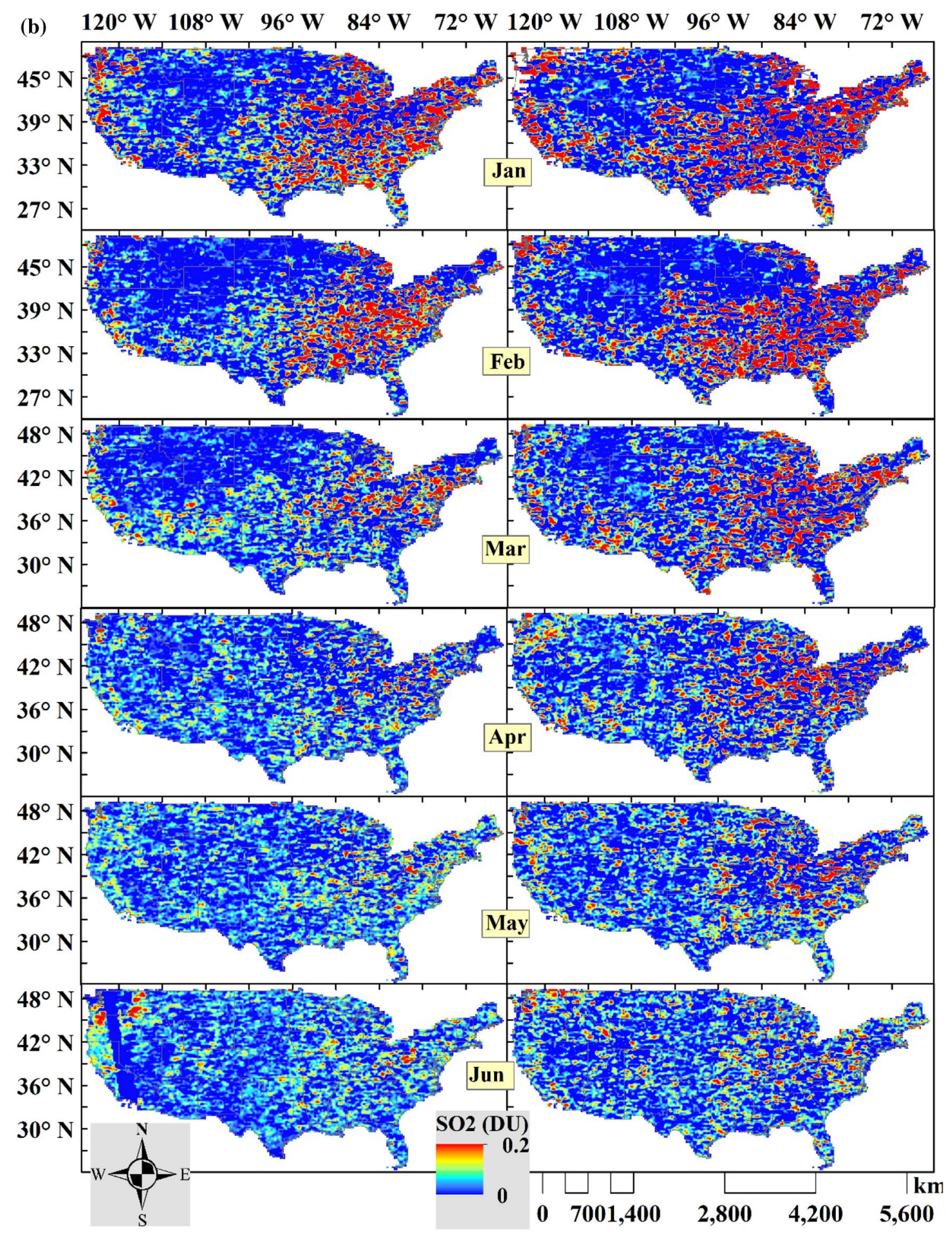

Fig. 9 (continued)

of the US. We found a decline in the aerosol loading that shows the decline in the aerosol's optical depth during May and June 2020. During March 2020, many cities show a rise in AOD (up to 136\%) whereas, during May and June, up to
$40 \%$ and $80 \%$ decline were observed. Significant changes are observed in the $\mathrm{PM}_{2.5}$ concentration over major locations and improvement in $\mathrm{PM}_{2.5}$ concentration during March-May 2020. But particulate matter concentration shows no major 
changes due to less dependence on anthropogenic emissions in comparison to most Asian countries. The changes in $\mathrm{NO}_{2}$ are quite prominent as tropospheric $\mathrm{NO}_{2}$ concentration decline, low ( -1 to $-6 \times 10^{15} \mathrm{~cm}^{-2}$ ) during March-April at major locations. Only three states show a positive shift in $\mathrm{NO}_{2}$ concentration during April-May, and other locations show a negative shift. We found positive changes in the total ozone concentration. But a sudden decline in Ozone concentration is seen during June 2020. These results show that the decline in tropospheric $\mathrm{NO}_{2}$ leads to a decline in tropospheric Ozone concentration and the total ozone column shows negative values during May and June 2020. The concentration of $\mathrm{SO}_{2}$ shows a positive shift especially in eastern parts during 2020 in comparison to long-term means as major emission of $\mathrm{SO}_{2}$ depends on Thermal power plants, Smelters, Gas, and Oil fields in the US. In the US, not much improvement in air quality and atmospheric aerosol optical depth was observed as was seen in India, China, and other countries. The reason could be that the lockdown was not strictly followed, the number of flights was cut down, but they were not stopped. People did not follow the rules implemented in different states, which shows US people are more relaxed, and they do not much care about their life, this could be because of economic conditions and indirectly show the social bonding among people compared to other countries especially in developing counties.

Author contributions RPS: conceptualization; RiM, AC: data analysis; RiM, AC, NCM, RoM: methodology; RiM, AC, NCM: Writing-original draft; AC, NCM, RPS: review and editing.

Data availability All the data used in the present study are freely available in the public domain; however, we will provide data to all the interested scientists.

\section{Declarations}

Conflict of interest The authors declare that they have no known competing financial interests or personal relationships that could have appeared to influence the work reported in this paper.

\section{References}

Acharya P, Barik G, Gayen BK, Bar S, Maiti A, Sarkar A, Ghosh S, De SK, Sreekesh S (2021) Revisiting the levels of Aerosol Optical Depth in south-southeast Asia, Europe and USA amid the COVID-19 pandemic using satellite observations. Environ Res 193:110514

Berman JD, Ebisu K (2020) Changes in US air pollution during the COVID-19 pandemic. Sci Total Environ 739:139864

Blumberg S (2020) Data shows 30 percent drop in air pollution over northeast U.S. Available at: http://www.nasa.gov/feature/godda rd/2020/drop-in-air-pollution-over-northeast. (Accessed 1 Jan 2021)
Burke M, Auffhammer M, Burney J, Hsiang S, Lobell D, Roberts M, Schlenker W (2020) COVID-19 reduces economic activity, which reduces pollution, which saves lives. Available at: www.g-feed. com/2020/03/covid-19-reduces-economic-activity. html (Accessed 28 Mar 2020)

Chakrabarty RK, Beeler P, Liu P, Goswami S, Harvey RD, Pervez S, van Donkelaar A, Martin RV (2021) Ambient PM2. 5 exposure and rapid spread of COVID-19 in the United States. Sci Total Environ 760:143391

Chauhan A, Singh RP (2020) Decline in PM2 5 concentrations over major cities around the world associated with COVID-19. Environ Res 187:109634

Chauhan AK, Singh RP (2021) Effect of lockdown on HCHO and trace gases over India during March 2020. AAQR. https://doi. org/10.4209/aaqr.2020.07.0445

Chen LW, Chien LC, Li Y, Lin G (2020) Nonuniform impacts of COVID-19 lockdown on air quality over the United States. Sci Total Environ 745:141105

Chinazzi M, Davis JT, Ajelli M, Gioannini C, Litvinova M, Merler S, Piontti APy, Mu K, Rossi L, Sun K, Viboud C (2020) The effect of travel restrictions on the spread of the 2019 novel coronavirus (COVID-19) outbreak. Science 368(6489):395-400

Elshorbany YF, Kapper HC, Ziemke JR, Parr SA (2021) The Status of air quality in the United States during the COVID-19 pandemic: a remote sensing perspective. Remote Sensing 13(3):369

Fioletov VE, McLinden CA, Krotkov N, Li C, Joiner J, Theys N, Carn S, Moran MD (2016) A global catalogue of large $\mathrm{SO}_{2}$ sources and emissions derived from the Ozone Monitoring Instrument. Atmos Chem Phys 16(18):11497-11519

Gharehgozli O, Nayebvali P, Gharehgozli A, Zamanian Z (2020) Impact of COVID-19 on the economic output of the US outbreak's epicenter. Econ Disasters Clim Change 4(3):561-573

Gilbert M, Pullano G, Pinotti F, Valdano E, Poletto C, Boëlle PY, d'Ortenzio E, Yazdanpanah Y, Eholie SP, Altmann M, Gutierrez B (2020) Preparedness and vulnerability of African countries against importations of COVID-19: a modelling study. The Lancet 395(10227):871-877

Kraemer MU, Yang CH, Gutierrez B, Wu CH, Klein B, Pigott DM, Du Plessis L, Faria NR, Li R, Hanage WP, Brownstein JS (2020) The effect of human mobility and control measures on the COVID-19 epidemic in China. Science 368(6490):493-497

Liu F, Page A, Strode SA, Yoshida Y, Choi S, Zheng B, Lamsal LN, Li C, Krotkov NA, Eskes H, Veefkind P (2020) Abrupt decline in tropospheric nitrogen dioxide over China after the outbreak of COVID-19. Sci Adv 6(28):2992

Rajbhandari B, Phuyal N, Shrestha B, Thapa M (2020) Air medical evacuation of Nepalese citizen during epidemic of COVID-19 from Wuhan to Nepal. J Nepal Med Assoc https://doi.org/10. 31729/jnma.4857

Singh RP, Chauhan A (2020) Impact of lockdown on air quality in India during COVID-19 pandemic. Air Qual Atmos Health 13(8):921-928

Wang C, Horby PW, Hayden FG, Gao GF (2020) A novel coronavirus outbreak of global health concern. The Lancet 395(10223):470-473

World Health Organization (2021a) WHO Coronavirus Disease (COVID-19) Dashboard. Available at: https://covid19.who.int. (Accessed 1 Jan 2021)

World Health Organization (2021b) Origins of the SARS-CoV-2 virus, Available at: https://apps.who.int/iris/bitstream/handle/ 10665/332197/WHO-2019-nCoV-FAQ-Virus_origin-2020.1eng.pdf. (Accessed 1 Mar 2021)

Xiang J, Austin E, Gould T, Larson T, Shirai J, Liu Y, Marshall J, Seto E (2020) Impacts of the COVID-19 responses on trafficrelated air pollution in a Northwestern US city. Sci Total Environ $747: 141325$ 
Zangari S, Hill DT, Charette AT, Mirowsky JE (2020) Air quality changes in New York City during the COVID-19 pandemic. Sci Total Environ 742:140496
Publisher's Note Springer Nature remains neutral with regard to jurisdictional claims in published maps and institutional affiliations. 